\title{
Climate-Agriculture-Modeling and Decision Tool (CAMDT): A software framework for climate risk management in agriculture
}

\author{
Eunjin Han ${ }^{\mathrm{a}, \mathrm{b}}$, Amor V.M. Ines b, c, *, Walter E. Baethgen ${ }^{\mathrm{a}}$ \\ a International Research Institute for Climate and Society, Columbia University, NY, 10964, USA \\ b Department of Biosystems and Agricultural Engineering, Michigan State University, MI, 48824, USA \\ ${ }^{\mathrm{c}}$ Department of Plant, Soil, and Microbial Sciences, Michigan State University, MI, 48824, USA
}

\section{A R T I C L E I N F O}

Article history:

Received 24 February 2017

Received in revised form

11 May 2017

Accepted 16 June 2017

\section{Keywords:}

CAMDT

DSSAT

Seasonal climate forecasts

Downscaling

Decision support system tool

\begin{abstract}
A B S T R A C T
Seasonal climate forecasts (SCFs) have received a lot of attention for climate risk management in agriculture. The question is, how can we use SCFs for informing decisions in agriculture? SCFs are provided in formats not so conducive for decision-making. The commonly issued tercile probabilities of most likely rainfall categories i.e., below normal (BN), near normal (NN) and above normal (AN), are not easy to translate into metrics useful for decision support. Linking SCF with crop models is one way that can produce useful information for supporting strategic and tactical decisions in crop production e.g., crop choices, management practices, insurance, etc. Here, we developed a decision support system (DSS) tool, Climate-Agriculture-Modeling and Decision Tool (CAMDT), that aims to facilitate translations of probabilistic SCFs to crop responses that can help decision makers adjust crop and water management practices that may improve outcomes given the expected climatic condition of the growing season.
\end{abstract}

(c) 2017 Elsevier Ltd. All rights reserved.

\section{Software and/or data availability}

Name of software CAMDT (Climate-Agriculture-Modeling and Decision Tool)

Developer International Research Institute for Climate and Society, Columbia University, NY, 10964, USA/ Michigan State University, East Lansing, MI, USA 48824

Contact Eunjin Han/Amor VM Ines, International Research Institute for Climate and Society, Columbia University, NY, 10964, USA. E-mail address eunjin@ iri.columbia.edu or inesamor@msu.edu

Year first available 2015

Hardware required PC

Software required Windows 2007 or higher version Program language Python and Fortran

Availability CAMDT Graphical User-Interface has been written in the Python programming language. Except for the Fortan codes, CAMDT is opensource. It can be freely downloaded from https://

Cost $\mathrm{N} / \mathrm{A}$

\section{Introduction}

The long-term impacts of climate change on food security have been studied extensively (Brown and Funk, 2008; Lobell et al., 2008; Schmidhuber and Tubiello, 2007). From a farmer's perspective, however, adaptation to climate change is more closely related to addressing risks associated with inter-annual climate variability than long-term changes or shifts in climate. During the past decades, advances in seasonal climate predictions have brought a great potential for improving climate risk management in agriculture (Capa et al., 2015; Hansen, 2005; Hansen et al., 2011; ShafieeJood et al., 2014). Seasonal climate forecast information have proven especially valuable in developing countries, particularly in tropical regions, which depend on rainfed agriculture and are vulnerable to climate extremes (flood, drought, and heat waves) due to limited technologies or infrastructure (Hansen, 2005).

Unlike weather forecasts, which are reliable at most for about one week in the future, seasonal climate anomalies can be predicted with a longer lead time (e.g., a few months) because they are linked to interactions between atmosphere and sea surface such as El-Niño-Southern Oscillation (ENSO) (Barnston et al., 2000). Due to the inherent uncertainty in climate prediction, most of the

\footnotetext{
* Corresponding author. Department of Plant, Soil, and Microbial Sciences, Michigan State University, 1066 Bogue St., East Lansing, MI, 48824 , USA.

E-mail addresses: eunjin@iri.columbia.edu (E. Han), inesamor@msu.edu (A.V.M. Ines), baethgen@iri.columbia.edu (W.E. Baethgen).
} 
publically accessible seasonal climate forecasts (SCF) released by the NOAA-Climate Prediction Center, the International Research Institute for Climate and Society (IRI) or the UK Met Office are provided in tercile probabilities of the most likely category, i.e., below normal (BN), near normal (NN) and above normal (AN), for rainfall and temperature.

Seasonal climate forecasts alone can fall short in providing actionable information for improving farm-level decisions and policy-level interventions. However, if SCFs are linked with a decision support system (e.g., with crop simulation models), they could help farmers improve strategic and tactical decisions to maximize benefits and minimize climate-related risks in the growing season. Yield Prophet (Hochman et al., 2009; http://www. yieldprophet.com.au) and AgroClimate (Fraisse et al., 2006; www. agroclimate.org) are some examples of Decision Support System (DSS), which can provide information on impacts of climate on crop growth/yield, disease occurrence, and recommended management practices based on several simulation models; climate forecasts used are often ENSO-based.

A major obstacle in integrating crop simulation models and SCFs is the mismatch of scales (space and time). Crop models require weather-scale inputs while SCFs provide seasonal climate information. Weather generators can generate synthetic daily weather data that crop models can use to run simulations (Buishand and Brandsma, 2001; Clark et al., 2004; Kim et al., 2016; Verdin et al., 2015; Wilks, 2002; Yates et al., 2003). However, they are not readily designed for linking probabilistic SCFs with crop models. Notwithstanding, by repurposing weather generators, several studies linked SCFs with crop simulation models by disaggregating SCF into daily weather sequences. Hansen and Indeje (2004) and Apipattanavis et al. (2010) applied stochastic disaggregation approaches to create daily weather sequences from SCFs to produce crop yield forecasts using DSSAT (Decision Support System for Agro-technology Transfer) crop simulation models (Jones et al., 2003; Hoogenboom et al., 2015).

Although SCFs are important for climate risk management, translating tercile-based (probabilistic) SCFs into agricultural terms is not straightforward. It requires some technical expertise, not only for running crop simulation models using the SCF median, but also in data science, computing and agronomy. It should be noted that all tercile probabilities of likely rainfall categories in the SCF (i.e., $\mathrm{BN}, \mathrm{NN}$ and $\mathrm{AN}$ ) comprise the full distribution (hence, information) of the forecast, opposite to the notion of taking the rainfall category with highest probability for convenience. When SCF is disaggregated to daily weather sequences, uncertainties in weather/ climate are reflected in the weather realizations. For instance, downscaling a $50 \% \mathrm{BN}, 30 \% \mathrm{NN}$ and $20 \%$ AN forecast can include 50 weather realizations extracted from the dry category, 30 from normal and 20 from wet, with a total of 100 realizations. Converting these weather realizations to model-specific format and running the crop model by the number of realizations can be a tedious and time-consuming task. Producing useful information from SCFs for decision support in agriculture is therefore a challenging task.

To help overcome these challenges, we developed a modelbased DSS tool, which can seamlessly integrate these procedures: disaggregate a given SCF, run a crop simulation model with the former and visualize model outputs such as expected yields or gross margins. Here, we present a DSS tool called ClimateAgriculture-Modeling and Decision Tool (CAMDT) that can aid in developing tailored information for agricultural decision-making using SCFs. CAMDT links SCFs with DSSAT crop models. In addition to a user-friendly graphical interface, CAMDT allows a user to run "what-if" scenarios, considering different climate forecasts or crop management options. CAMDT also includes a simplified integrated climate-crop-economic modeling system that can translate crop model outputs into economic terms.

\section{Software description}

CAMDT is a DSS tool with a simple, user-friendly interface, which aims to integrate SCF temporal downscaling tools (predictWTD or FResampler1, will be described later) and DSSAT. This version of CAMDT is linked with DSSAT-CSM-Rice model, although there is a potential of including other crop models in the future. A Graphical User Interface (GUI) serves as a wrapper that integrates SCF and crop model based on user's inputs. CAMDT requires lesser inputs from users compared with the regular DSSAT interface. Users with little experience in DSSAT or SCF downscaling methods can use CAMDT to generate tailored information for agricultural decisions. In addition, the software is designed to help users avoid the tedious tasks of creating format-sensitive DSSAT input files, and extracting target output variables out of several DSSAT output files for analysis. CAMDT can easily display direct DSSAT outputs (e.g., yield and water stress), as well as translated outputs (e.g., risk of water stress and gross margins). It is envisaged that the software can contribute to developing better informed climate adaptation strategies by providing users the ability to easily assess scenarios of various agronomic practices, given an expected seasonal climate. SCF downscaling only includes rainfall in this version, but a similar approach can be easily expanded to include other variables such as temperature.

\subsection{DSSAT-CSM-rice model}

The DSSAT-Cropping System Model (CSM) is a modular-based application package, which can simulate at least 16 different crops (Hoogenboom et al., 2015; Jones et al., 2003). The crop models simulate crop growth and development, soil moisture, carbon and nitrogen dynamics under specific management practices at a spatially uniform field. Weather data including daily maximum and minimum air temperature $\left(\mathrm{T}_{\max }\right.$ and $\left.\mathrm{T}_{\min }\right)$, solar radiation and precipitation, are fundamental forcing variables to simulate hydrological processes and crop phenology. Temperature is used to estimate growing degree-days which determine the rate of crop development (Jones et al., 2003). Soil properties are also critical variables to simulate water, carbon and nitrogen dynamics in the soil and their impacts on crop growth. Soil information required by DSSAT includes physical, chemical and morphological characteristics of each soil layer. Crop growth stages are simulated based on user-determined genetic coefficients which vary with different cultivar types. Therefore, genetic coefficients of a target cultivar should be properly calibrated and tested using field experimental data before the models are used for any application. Biomass production of a crop is determined mainly by intercepted photosynthetically active radiation (PAR), and penalized by several stress factors, such as extreme temperature or limited water or nitrogen availability.

As mentioned, this version of CAMDT linked DSSAT-CSM-Rice model with SCF to simulate rice growth and development. To simulate irrigated low-land rice, transplanting dates and detailed irrigation schedules need to be provided. More details on the rice model can be found in Ritchie et al. (1998) and Jones et al. (2003). Like other crop simulation models, DSSAT-CSM-Rice model has been used on a wide range of applications including: identifying optimal management options (Ahmad et al., 2012; Amiri et al., 2013); estimating rice yields (Mahmood et al., 2003); assessing impact of climate change on rice yields (Basak et al., 2009; Saseendran et al., 2000), simulating interactions between pest damage and rice yields (Pinnschmidt et al., 1995), among others. 


\subsection{Temporal downscaling of seasonal climate forecasts}

This current version of CAMDT includes two downscaling (temporal) methods to link SCFs with the DSSAT-CSM-Rice model: (i) parametric, predictWTD (Ines and Han, 2014) and (ii) nonparametric, FResampler1 (Ines, 2013). The predictWTD is a spinup of the works of Hansen and Ines (2005) on conditional stochastic weather generator, but downscales the full distribution of SCF, not just the median. A stochastic weather generator can be constrained to generate rainfall realizations that match a target rainfall amount, or can be conditioned by altering rainfall intensity and/or frequency parameters based on a forecast (Hansen and Indeje, 2004; Hansen and Ines, 2005; Ines et al., 2011).

In predictWTD, a tercile-based probabilistic seasonal climate forecast is first converted to a theoretical cumulative density function (CDF) curve. Then, seasonal rainfall amounts are extracted that correspond to 5 th, 15 th, ..., 95th percentile of the forecast CDF. These samples represent the SCF distribution. These seasonal deviates are converted to monthly values based on climatology. Consequently, monthly rainfall amounts can be transformed to rainfall intensities or frequencies using the mass conservation equation of rainfall $(R=\mu \times \pi)$, where $R$ is total rainfall ( $\mathrm{mm} /$ day), $\mu$ is rainfall intensity ( $\mathrm{mm} /$ wet-day) and $\pi$ is rainfall frequency (wetday/day). Using forecasts $R, \mu, \pi$ or combinations from those 10 representative percentiles the SCF is downscaled into daily rainfall realizations by constraining/conditioning the stochastic weather generator. Solar radiation and temperature (maximum and minimum) are also generated conditioned on rainfall occurrence, but model parameters were not altered from climatology in this CAMDT version. Nevertheless, the current stochastic model can downscale monthly temperature and solar radiation to daily sequences, if needed. Details of the conditional stochastic weather generators can be found in Hansen and Indeje (2004) and Hansen and Ines (2005).

FResampler1 uses the concept of "conditional block sampling" of weather data to create daily weather realizations of a tercilebased probabilistic seasonal climate forecasts. For a season of interest, it draws randomly from historical records a set of daily weather data (rainfall, $\mathrm{T}_{\min }, \mathrm{T}_{\max }$ and solar radiation) from years that belong to a certain rainfall tercile category (i.e., BN, NN or AN). In this way, FResampler1 preserves the covariance between rainfall and other weather parameters, as values of $\mathrm{T}_{\min }, \mathrm{T}_{\max }$ and solar radiation are conditional on rainfall.

A sensitivity analyses of factors impacting performance of predictWTD and FResampler1 were presented in Han and Ines (2015). The performances of these two methods were compared by Capa et al. (2015), who investigated impacts of SCF on maize and wheat yields and irrigation requirements in the Iberian Peninsula. They suggested that these methods could be considered as feasible options when linking SCF with crop simulation models. Since FResampler1 samples daily weather data from historical records, with replacement, observations of at least 30 years are required for reasonable outcomes. This assumption on data requirement holds true for predictWTD.

\subsection{Linking SCF with DSSAT through CAMDT user-interface}

The DSSAT software package provides a good user-interface and supplementary tools for creating input files and analyzing model results. CAMDT expands the utility of DSSAT crop models to seamlessly integrate probabilistic SCF to support decision-making in agriculture. CAMDT requires more simplified input information for DSSAT simulations and it has the functionality to adjust rooting depth of a given soil profile as deep-, medium- or shallow-depth soil. There have been several studies that tried to link SCFs to crop simulation models by disaggregating the SCFs into daily weather data (Apipattanavis et al., 2010; Hansen and Indeje, 2004; Hansen and Ines, 2005; Pal et al., 2013). However, the procedures are cumbersome and time consuming, and do not use the full information of a probabilistic SCF. CAMDT provides a convenient interface for coupling SCF and DSSAT-CSM-Rice model to predict yield, perform scenario analysis on crop, fertilizer and water management combinations, and for conducting economic analysis.

CAMDT's Graphical User Interface (GUI) was developed using Tkinter module and Pmw megawidgets in Python (www.phyton. org). CAMDT has the flexibility to be updated in order to add more functionalities in the future. It can be easily customized to meet specific needs (e.g., simulating different crops) for climate risk management in other regions. Since Python is free and opensource, CAMDT can be easily adopted without licensing issue, which is beneficial, especially for developing countries; this is particularly interesting because DSSAT is now free as well. Except for the Fortan codes, CAMDT is open-source. It can be freely downloaded from: https://github.com/EunjinHan/CAMDT_ Philippines. Fig. 1 shows the first tab (Simulation setup) of CAMDT GUI.

Fig. 2 shows the schematic of procedures implemented in CAMDT. The current version of CAMDT can be used for "hindcast" or "forecast" analysis. Hindcast is used when one wants to perform a retrospective analysis wherein the performance of the seasonal climate forecast and DSSAT are evaluated. Forecast is used for exante analysis. CAMDT can read SCF's tercile probabilities from ASCII file generated by IRI's Climate Predictability Tool (CPT) (Mason and Tippett, 2016) or can be inputted manually.

Long-term historical weather data is required to calibrate stochastic models for predictWTD, or to provide enough sampling space for FResampler1. FResampler1 requires only the number of realizations as input from the user. The predictWTD requires additional inputs e.g., monthly target values either as rainfall amount, frequency, intensity or any combinations of these variables to constrain/condition the stochastic models.

Two different time horizons are needed to be specified in CAMDT: target growing season (from planting to harvesting) for DSSAT simulations, and target forecast season for a SCF. If SCF is applied at the beginning of the growing season, all simulations are forced by downscaled weather realizations, resulting in larger uncertainty of the predicted yields. If the SCF is applied in the middle of the growing season, observed weather data is used until the start of the target forecast season, resulting in lesser uncertainties of the predicted yields.

CAMDT can perform "what-if" scenarios. Forecasted yields of all scenarios are plotted for comparison, either by box-plots or exceedance probability curves. Exceedance probability $(P)$ is computed as $P=m \times(n+1)^{-1}$ where $m$ is the rank of a forecasted yield ( $m=1$ is the largest value) and $n$ is the total number of simulated years (yields). Uncertainties in forecasted yields are reflected by the spread of the probability curves or middle quartiles of the boxplots. Gross margins can be also plotted as either box-plots or exceedance probability curves. Time series of average water stress defined as, 1- $\mathrm{ET}_{\mathrm{a}} / \mathrm{ET}_{\mathrm{p}}$, where $\mathrm{ET}_{\mathrm{a}}$ and $\mathrm{ET}_{\mathrm{p}}$ are actual and potential evapotranspiration, respectively are also visualized. In addition, the risk of exceeding a water stress threshold can be plotted as well.

\section{Study area: Bicol province, Philippines}

This version of CAMDT was developed for rice-based agricultural systems in Bicol River Basin, Philippines (Fig. 3). The Bicol River Basin is one of the major basins in the country covering approximately $3770 \mathrm{~km}^{2}$ of catchment area. Agriculture and 


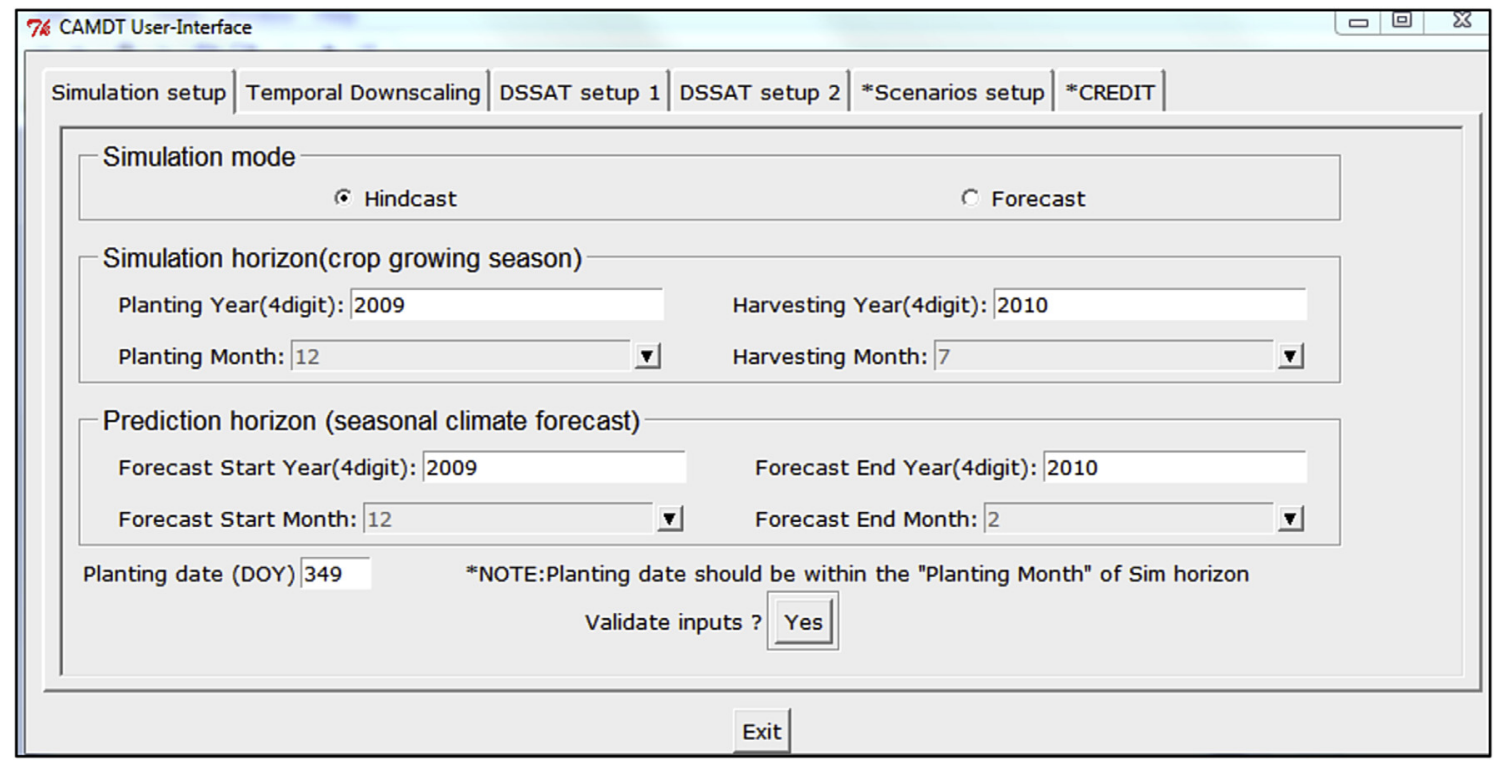

Fig. 1. Graphical user-interface of CAMDT.

fisheries are the major sources of income in the region. The Bicol region is highly vulnerable to climate-related risks, mainly typhoons and floods. However, droughts or dry spells also negatively affect rice farming in the Bicol region (Elazegui et al., 2016). Ella et al. (2010) ascribed inequitable distribution and inadequate supply of irrigation water to climate change/variability and deteriorating watershed conditions. As a result, there have been conflicts among water users of Lake Buhi (agriculture, fisheries, municipality and hydroelectric power generation). Therefore, climate-smart agricultural water use became more of an important issue in the Bicol region, in spite of high annual rainfall (Fig. 4).

Climate and rice production in the Philippine are strongly influenced by ENSO (Koide et al., 2013; Lyon and Camargo, 2009; Lyon et al., 2006). Seasonal rainfall in many regions of the country are usually lower during El Niño and higher during La Niña (Jose et al., 1999; Mason and Goddard, 2001). Seasonal climate forecasts in the Bicol region have higher skill in the October-NovemberDecember (OND) season than the rest of the year (Lyon et al., 2006). Koide et al. (2013) found a strong relationship between rainfall in OND and rice production (both rain-fed and irrigated) for the dry cropping season (January-June). SCFs with better skill and enough lead-time may thus benefit farmers allowing more opportunities to reduce climate risks in their agricultural activities.

In the Bicol region, there are only two weather stations with long-term climate records for DSSAT simulations and downscaling of SCF (Fig. 3). The weather stations in Pili (PILI) and Legaspi City (LEGA) have daily weather observations $\left(\mathrm{T}_{\min }, \mathrm{T}_{\max }\right.$ and precipitation) since 1975 and 1984, respectively. For this study, we used solar radiation data from NASA- Prediction of Worldwide Energy Resource (POWER) (http://power.larc.nasa.gov/). Monthly $\mathrm{T}_{\max }$ and $\mathrm{T}_{\min }$ in PILI and LEGA show little variations throughout the year (Fig. 4). Monthly rainfall distribution is different for the two stations. LEGA station shows a Type II climate, which has no clear dry season with maximum rainfall in November and December affected by the northeast monsoon. PILI has a Type IV climate with relatively low rainfall that occur from January to May while relatively high rainfall occur from June to December (Koide et al., 2013).

Bicol Region has two rice growing seasons with planting in June and December (Table 1). The region heavily depends on irrigation for rice farming; 70-90\% of rice production comes from irrigated fields (Koide et al., 2013).

Soil properties are one of the critical inputs for DSSAT. Due to unavailability of a local soil database, we extracted five soil profiles located in the Bicol region from WISE (World Inventory of Soil Emission Potentials) soil database Romero et al. (2012). A total of 15 different soil types are available in CAMDT for the Bicol region.

\section{Calibration and validation}

Although CAMDT can be used for yield forecasting, it is not a platform intended to establish yield forecasts, but to inform decisions by assessing the expected impact of technology options on crop yields and income, for different seasonal climate scenarios. Thus, the main purpose of running CAMDT is to optimize agronomic practices according to expected climate conditions. Therefore, evaluating the performance of CAMDT is not as simple or straightforward as calibrating/validating traditional crop simulation models such as DSSAT because CAMDT links DSSAT to "probabilistic" SCF. Therefore, evaluation of CAMDT performance can be conducted in two different perspectives: evaluation of DSSAT performance and accuracy of a tercile-based SCF.

\subsection{DSSAT-CSM-rice calibration}

Two rice cultivars (PSB Rc82 and Mestiso 20) were calibrated based on field experiments by Philippine Rice Research Institute (PhilRice). The experiments were conducted during dry (sowing in December) and wet (sowing in July) seasons in 2012 with different fertilizer applications. Several observed data (e.g., panicle initiation day, dates of anthesis and physiological maturity, yield at harvest/ maturity) from the experiments were used in GENCALC (Genotype Coefficient Calculator in DSSAT4.6; Hoogenboom et al., 2015) for calibration. Table 2 shows calibrated genetic coefficients for each cultivar, where P1- thermal time required for the plant to develop from after emergence to end of juvenile stage, P2R - rate of photoinduction, P5 - thermal time for grain filling, P2O - optimum photoperiod, G1 - potential spikelet number coefficient, G2 - single grain weight under ideal growing conditions, G3 - tillering 


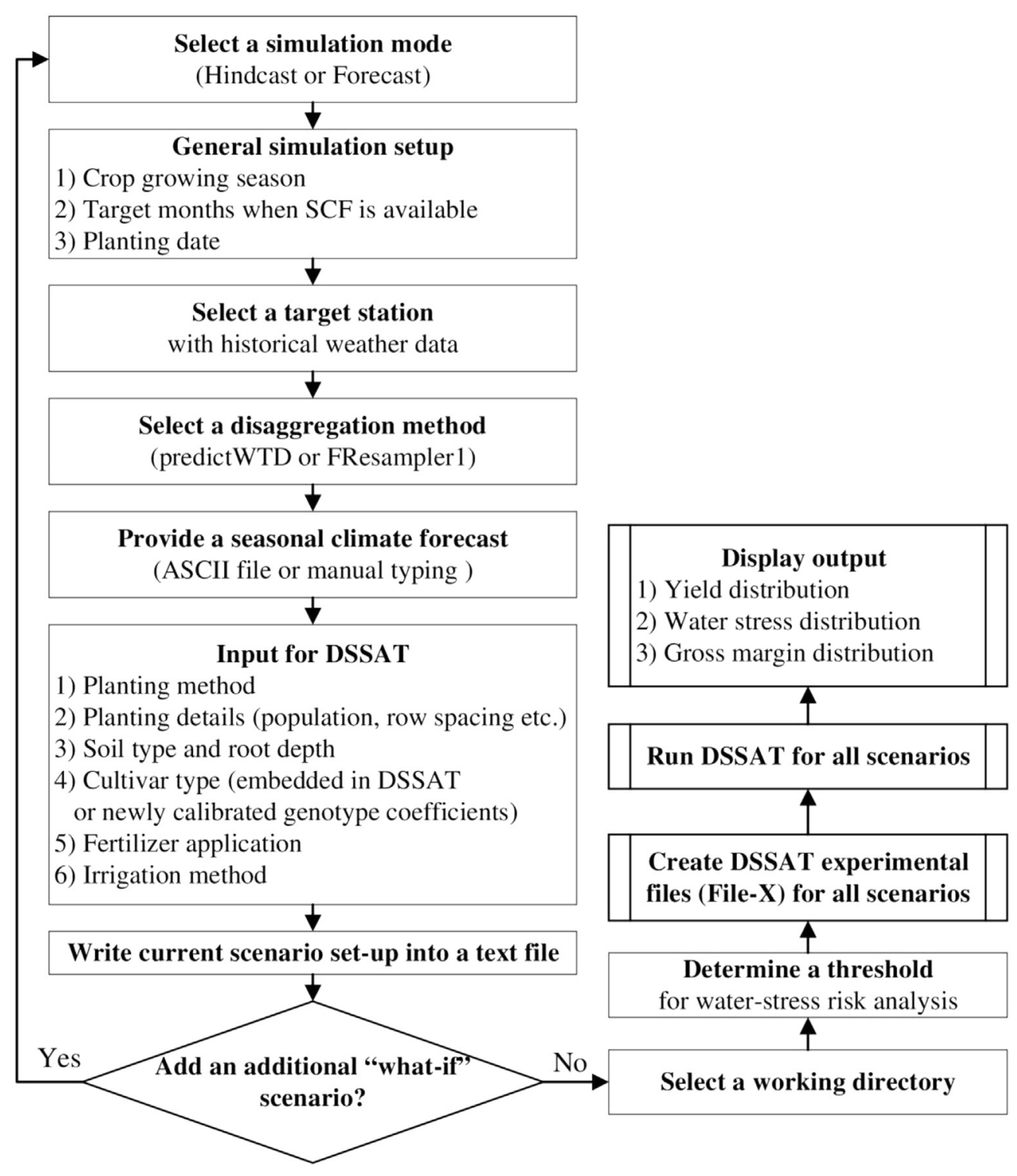

Fig. 2. Schematic of CAMDT processes.

coefficient and G4 - temperature tolerance coefficient (Ritchie et al., 1998; Hoogenboom et al., 2015). Table 3 shows the performance of the calibrated cultivar coefficients. In general, physiological development and biomass responses were simulated relatively well, with some noticeable errors on anthesis dates and yield simulations, in the wet season. Details of the calibration study including comparisons of calibration methods will be presented in future publications. Other rice cultivars are included in the current version of the CAMDT.

\subsection{DSSAT-CSM-rice evaluation}

DSSAT-simulated yields with long-term daily weather data from PILI and LEGA stations were compared with the historical rice yields at Camarines Sur and Albay Province in Bicol (http://dbmp. philrice.gov.ph/Ricestat/Statmonth\%20data/Volume_1yield.html). The comparisons were conducted for years, which have both yield statistics and daily weather data at local weather stations (1976-2015 for PILI and 1985-2015 for LEGA).
Historical rice yields were de-trended to filter non-climate signals in rice yield variability. Spearman's rank correlation was used to quantify how simulated yields correspond with the detrended observed yields at a provincial level. Considering heterogeneities in soil characteristics, weather, management practices, rice cultivars at the provincial level, simulated and observed yields were normalized for comparison. Simulated rainfed rice yields using PILI weather data showed reasonable correlation $(\rho=0.401$, p-value $=0.010)$ with rainfed yields in Camarines Sur (Fig. 5a). Simulated yields using LEGA weather data also showed good correlation $(\rho=0.512$, $p$-value $=0.003)$ with observed yields in Albay (Fig. 5b). These results show that DSSAT responds adequately with climate variability in the two provinces. Some opposite variations between the simulated and observed yields were apparent (e.g., 2014 in Pili), which could be attributed to processes that DSSAT could not simulate (e.g., disease or physical damage due to strong wind and flood). Rigorous crop model validation can be done at the field level, but is not the scope of this study. 


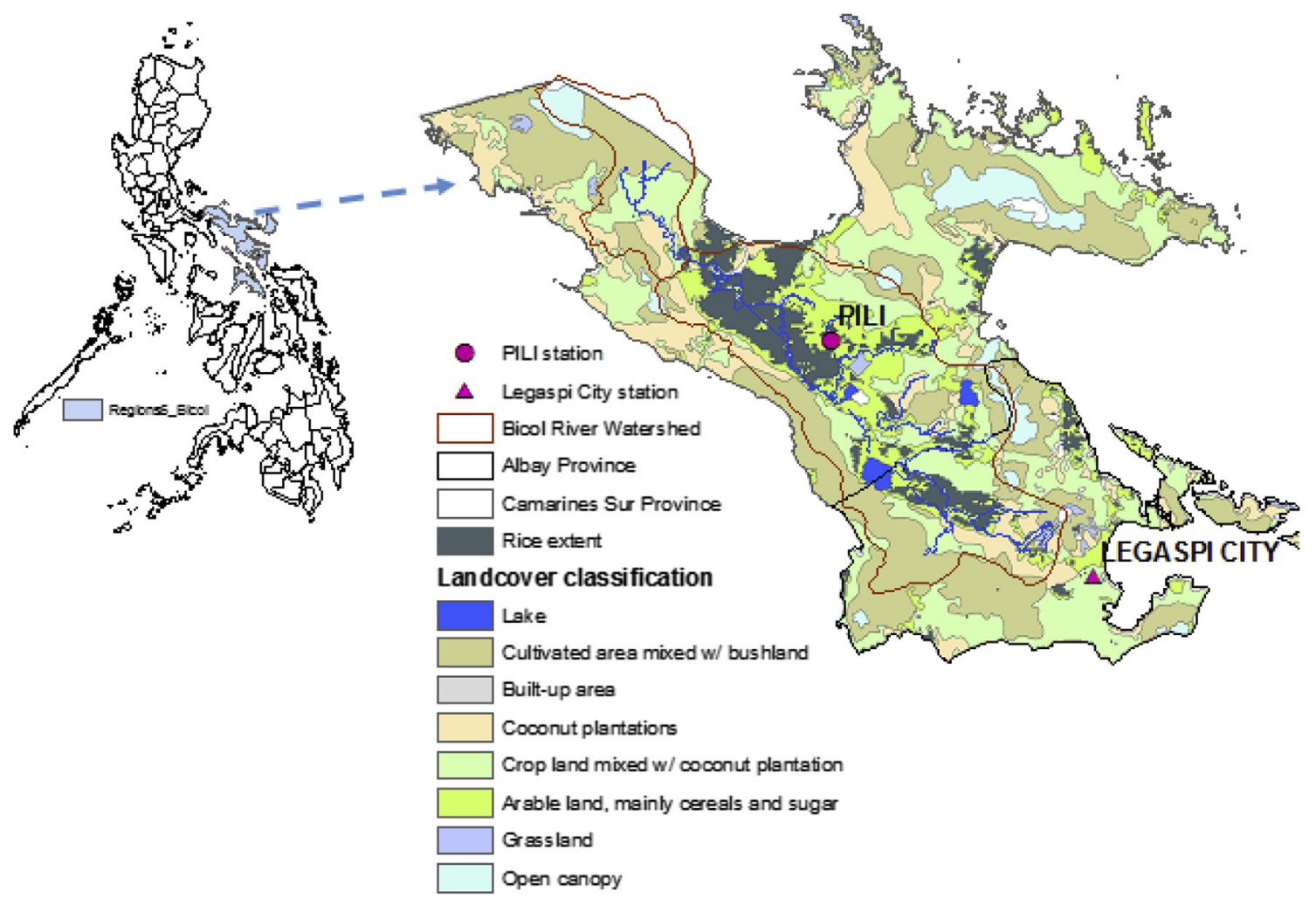

Fig. 3. Map of Bicol region.

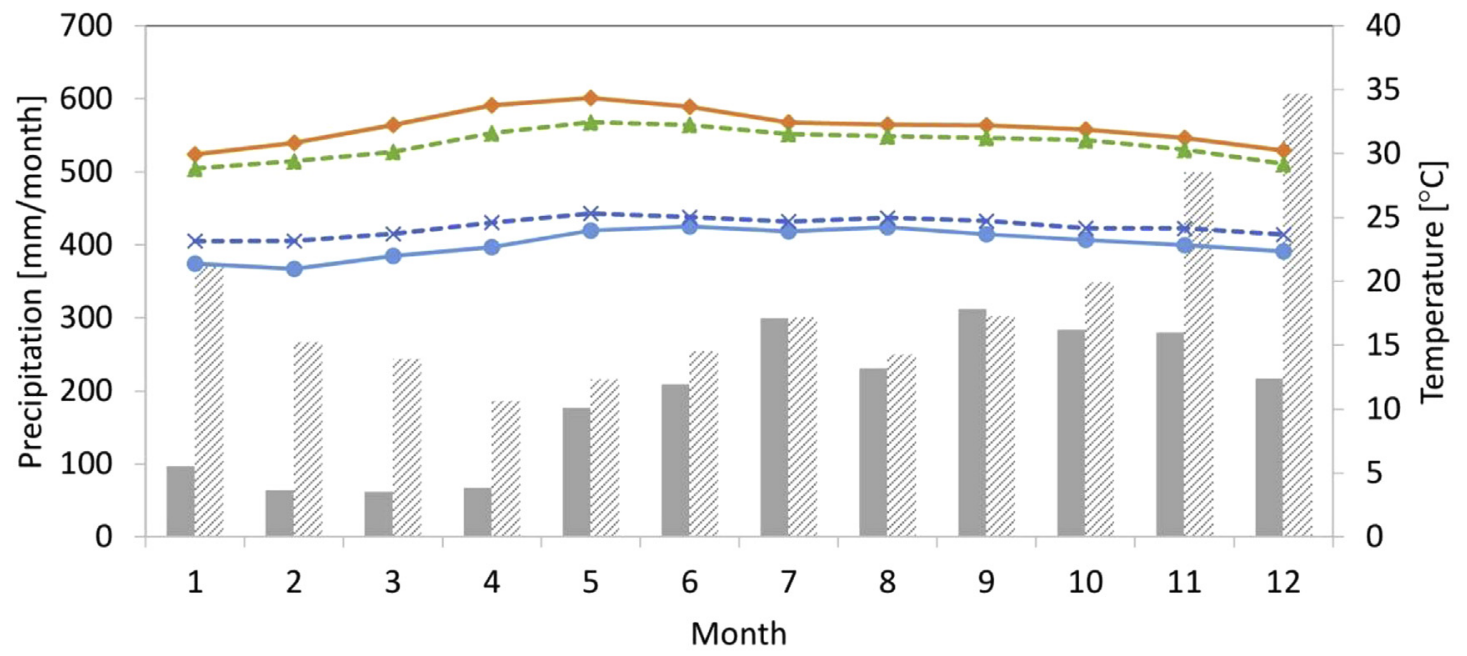

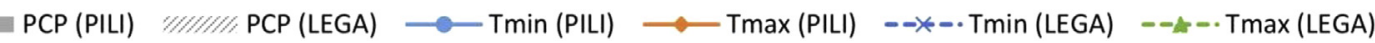

Fig. 4. Monthly average maximum and minimum temperature $\left(T_{\max }\right.$ and $T_{\min }$ ) and precipitation (PCP) observed at PILI and LEGA.

\subsection{Seasonal climate forecast accuracy}

Potential predictability of SCF in the Philippines is high due to its strong connection with ENSO events (El Niño and La Niña), specifically for the drier season from October to March (Lyon et al., 2006). Therefore, climate predictions with enough lead-time could greatly benefit the agricultural sector. We used CAMDT to validate the benefits of SCF for forecasting rice yields in the Bicol region. Tailored SCF for the Bicol region produced by CPT (Lyon and Ines, 2014; Mason and Tippett, 2016) was used in this experiment.
Two ENSO years were tested, a very wet SCF (4\% BN, 13\% NN and $83 \%$ AN) for JFM of 2009 due to La Niña (LaNi) and a drier SCF (40\% $\mathrm{BN}, 39 \% \mathrm{NN}$ and $21 \% \mathrm{AN}$ ) for JFM of 2010 due to El Niño (ElNi). As reference, climatology (CL) (33\% BN, 34\% NN and 33\% AN) was also compared with those two years. It was assumed that rice was transplanted December 15th and fertilizer was applied twice, 17th and 32 nd days after planting ( $35 \mathrm{~kg} \mathrm{~N} \mathrm{ha}^{-1}$ in each date). Irrigation was applied only during transplanting to make the soil saturated. Weather data from the PILI station, calibrated PSB Rc82 rice cultivar, and sandy clay loam soil were used in this experiment. A set of 100 
Table 1

Rice calendar in the Bicol region, Philippines.

\begin{tabular}{lll}
\hline & $\begin{array}{l}\text { Day-of-year } \\
\text { (First season) }\end{array}$ & $\begin{array}{l}\text { Day-of-year } \\
\text { (Second season) }\end{array}$ \\
\hline Onset of planting & 152 (June 1) & 335 (December 1) \\
Peak planting date & 166 (June 15) & 349 (December 15) \\
End of planting & 181 (June 30) & 365 (December 31) \\
Onset of harvest & 244 (September 1) & 74 (March 15) \\
Peak harvest date & 258 (September 15) & 74 (March 15) \\
End of harvest & 273 (September 30) & 90 (March 31) \\
Growing period from sowing to harvesting [days] & 92 & 90 \\
\hline
\end{tabular}

*source: http://irri.org/our-work/research/policy-and-markets/mapping-rice-in-the-philippines-when

Table 2

Calibrated genetic coefficients.

\begin{tabular}{lllllllll}
\hline Cultivar & P1 & P2R & P5 & P2O & G1 & G2 & G3 & G4 \\
\hline PSB Rc82 (Dry Season) & 447.9 & 4.4 & 420.0 & 11.9 & 88.6 & 0.025 & 1.00 & 1.00 \\
PSB Rc82 (Wet Season) & 627.6 & 3.5 & 340.2 & 9.4 & 125.9 & 0.025 & 1.00 & 1.00 \\
Mestiso 20 (Dry Season) & 629.6 & 3.5 & 533.6 & 9.4 & 65.9 & 0.025 & 1.00 & 1.00 \\
\hline
\end{tabular}

Note: Refer to Jones et al. (2003) for definition of parameters; PHNT parameter was fixed at 83 .

daily weather realizations were created for each scenario by predictWTD.

As shown in Fig. 6a, the means of predicted yields with wet or dry SCF were closer to the yields simulated with observed weather (dots) compared with the predicted yields with climatology (CL09 and CL10) in El Niño (ElNi) and La Niña (LaNi) years. These results suggest that tailored SCFs have predictive skills, and a reliable SCF can provide useful information for predicting yields more accurately, early enough before harvesting to be able to prepare effectively for countermeasures in advance. In the El Niño year (2010), the dry forecast resulted in stronger water deficit, hence lower yields (Fig. 6b). In the La Niña year (2009), there were no water stress (Fig. 6b), but less solar radiation or unfavorable temperatures might have negatively impacted photosynthesis resulting in lower yields than climatology.

The soil water deficit in the El Niño year (2010) hampered crop growth by limiting water uptake by the plants. Extreme dry conditions that occurred after planting (December 15, 2009) lowered the surface soil water content near wilting point due to no irrigation and thus the fertilizer applied by DSSAT on 17 days after planting (DAP) was not fully utilized resulting in extreme nitrogen stress from 26 DAP. However, the La Niña condition early in 2009, continuously saturated the soil after planting (December 15, 2008) thereby providing a more favorable condition for fertilizer to be available to the plants resulting in lower nitrogen stress during crop development. Median yield simulated by SCF under El Niño condition was closer to 'observed' than yield simulated using climatology. Larger spreads, however, can be attributed to the still moderate portions of the simulations coming from NN and AN categories, compounded by drier events in the forecast season
(JFM) and observed weather (December 2009).

\section{Case studies}

In this section we show how CAMDT can be used for agricultural decision support given an expected SCF.

\subsection{Effects of different fertilizer applications}

Optimal application of fertilizer, especially nitrogen $(\mathrm{N})$ is one of the key elements for sustainable cropping systems (Ahmad et al., 2012). Effects of different fertilizer applications on yields were tested with a cultivar PSB Rc82 and a sandy clay loam soil profile. The rice transplanting date was December 15, 2009 (peak planting date for the dry season). Due to El Niño, a drier SCF 45\% BN, 35\% NN and $20 \%$ AN was applied for JFM of 2010 . The parametric downscaling method, predictWTD was used to disaggregate SCF to daily weather realizations constraining rainfall amount and adjusting rainfall frequency parameters (e.g., Ines et al., 2011). To focus on the effects of fertilizer applications, no water stress was assumed by applying the automatic irrigation. LEGA weather data was used in the simulations (Fig. 4). Note that even in this simulation setup, crop simulations could be still affected by the drier SCF e.g., the impact of stronger solar radiation in crop production compared to climatology (Fig. 7). DSSAT, with its native user-interface, can be set-up to simulate these fertilizer treatments using observed weather, but linking it with the probabilistic SCF is cumbersome at most, without specialized tools (Hansen and Ines, 2005; Ines et al., 2011). CAMDT bridges that gap. The intent of this case is to showcase that capability.

The first scenarios applied no fertilizer, using SCF (FRF0) and climatology (FRCO). Second scenarios included a two-time fertilizer application, $35 \mathrm{~kg}$ of $\mathrm{N} \mathrm{ha}^{-1}$ applied on 17 DAP and 32 DAP, using SCF (FRF1) and climatology (FRC1). The last scenario had the same amounts of fertilizer as the second scenarios, but one more appli-

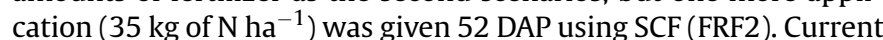
version of CAMDT can only accommodate five scenarios at the moment. Since the predefined fertilizer set-up was applied for both SCF and climatology, the results cannot be interpreted as SCF informing decision on fertilizer applications (this capability will be added in future CAMDT versions). It can show, however, the impact

Table 3

Performance metrics of calibrated genetic coefficients.

\begin{tabular}{|c|c|c|c|c|c|c|c|c|c|}
\hline \multirow[t]{2}{*}{ Cultivar } & \multicolumn{3}{|c|}{ Days to anthesis } & \multicolumn{3}{|c|}{ Days to maturity } & \multicolumn{3}{|c|}{ Grain yield $\left(\mathrm{kg} \mathrm{ha}^{-1}\right)$} \\
\hline & Obs. & Sim. & Error (\%) & Obs. & Sim. & Error (\%) & Obs. & Sim. & Error $(\%)$ \\
\hline $\begin{array}{l}\text { PSB Rc82 } \\
\text { (Dry Season) }\end{array}$ & 56 & 56 & 0 & 95 & 90 & 5.26 & 9497 & 9299 & 2.08 \\
\hline $\begin{array}{l}\text { PSB Rc82 } \\
\text { (Wet Season) }\end{array}$ & 76 & 65 & 14.47 & 90 & 90 & 0 & 6975 & 5465 & 21.64 \\
\hline Mestiso 20 (Dry Season) & 78 & 69 & 11.54 & 107 & 107 & 0 & 9926 & 9921 & 0.05 \\
\hline
\end{tabular}



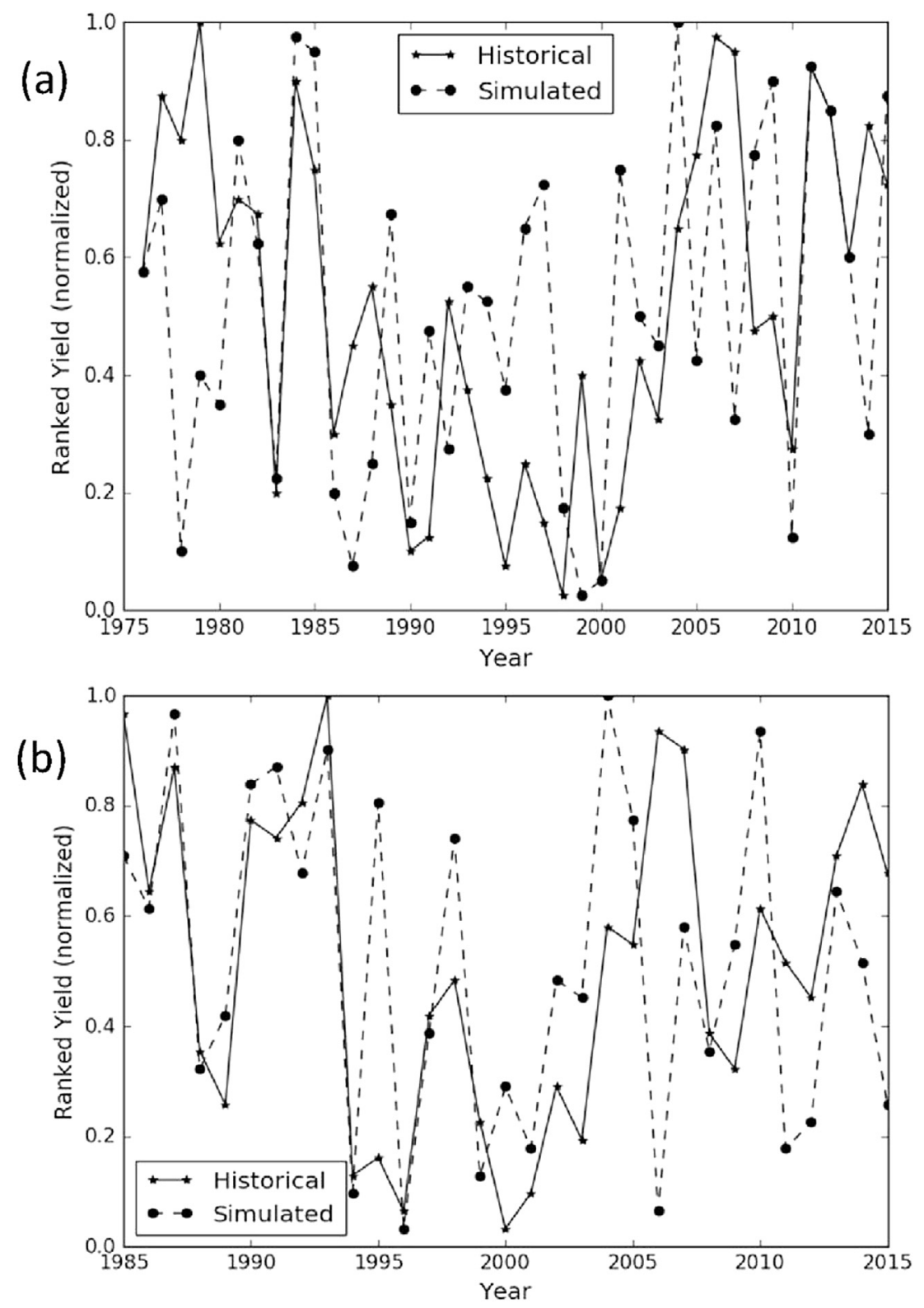

Fig. 5. Ranked observed and simulated yields a) Province of Camarines Sur with PILI station and b) Province of Albay with LEGA station.

of fertilizer to crop growth, which regular DSSAT can provide (after post processing), and the value of SCF to predicting crop yields.

Fig. 7 shows the forecasted yields from the fertilizer scenarios. Compared to the reference case (FRF0), FRF1 and FRF2 produced lesser variances in yield distribution and higher yields as expected. Compared to climatology, the drier SCF resulted in slightly higher yields for both reference cases (FRF0, FRC0) and with fertilizer application cases (FRF1, FRC1). We observed that excessive water under climatology caused more nitrogen $(\mathrm{N})$ leaching resulting to more nitrogen $(\mathrm{N})$ stress during the critical growth stage (reproductive) (Fig. 8).

Next, in addition to the yield forecast, expected gross-margin was also generated based on the different management practices as shown in Fig. 7c and d. This economic analysis provides additional practical information that can further assist farmers' decision making. In this exercise, rice price, cost of nitrogen fertilizer, cost of irrigation and general costs were assumed as 425 USD ton $^{-1}, 1.0$ USD $\mathrm{kgN}^{-1}, 0.3 \mathrm{USD}^{-1}$ and $800 \mathrm{USD}^{-1}$ respectively. Fig. 7 shows higher yields and gross margins as more fertilizer was applied. However, there would be a critical point where increased fertilizer amounts would result in a decrease in gross margin. This analysis can be modified to find optimal amounts or timing of fertilizer application or to investigate yield gaps due to insufficient or inefficient management practices.

\subsection{Effect of different planting dates}

In rainfed systems, adjusting planting windows can make a big difference in yields. Here we tested three different planting dates (December 1st, 15th and 31st, DOY335, DOY349 and DOY365, respectively) for the second cropping season (Table 1 ), which is vulnerable to dry spells or drought. The PILI station was selected because it has less rainfall during the second cropping season than the first (Fig. 4). El Niño strongly affects the Bicol region increasing the chances of weather conditions that are drier than climatology during the second cropping season. For instance, in December 2015, 

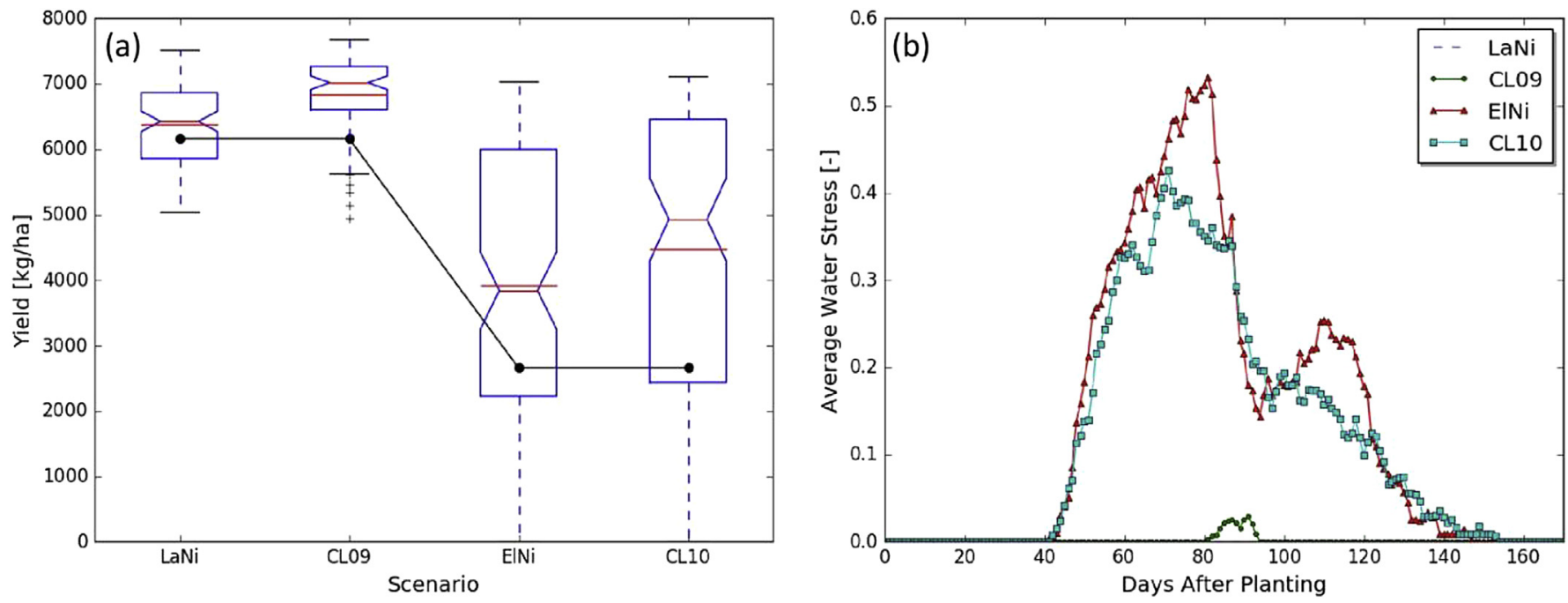

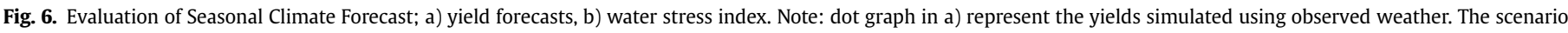

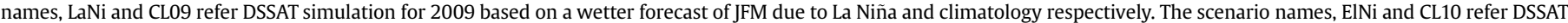
simulation for 2010 based on a drier forecast of JFM due to El Niño and climatology respectively.
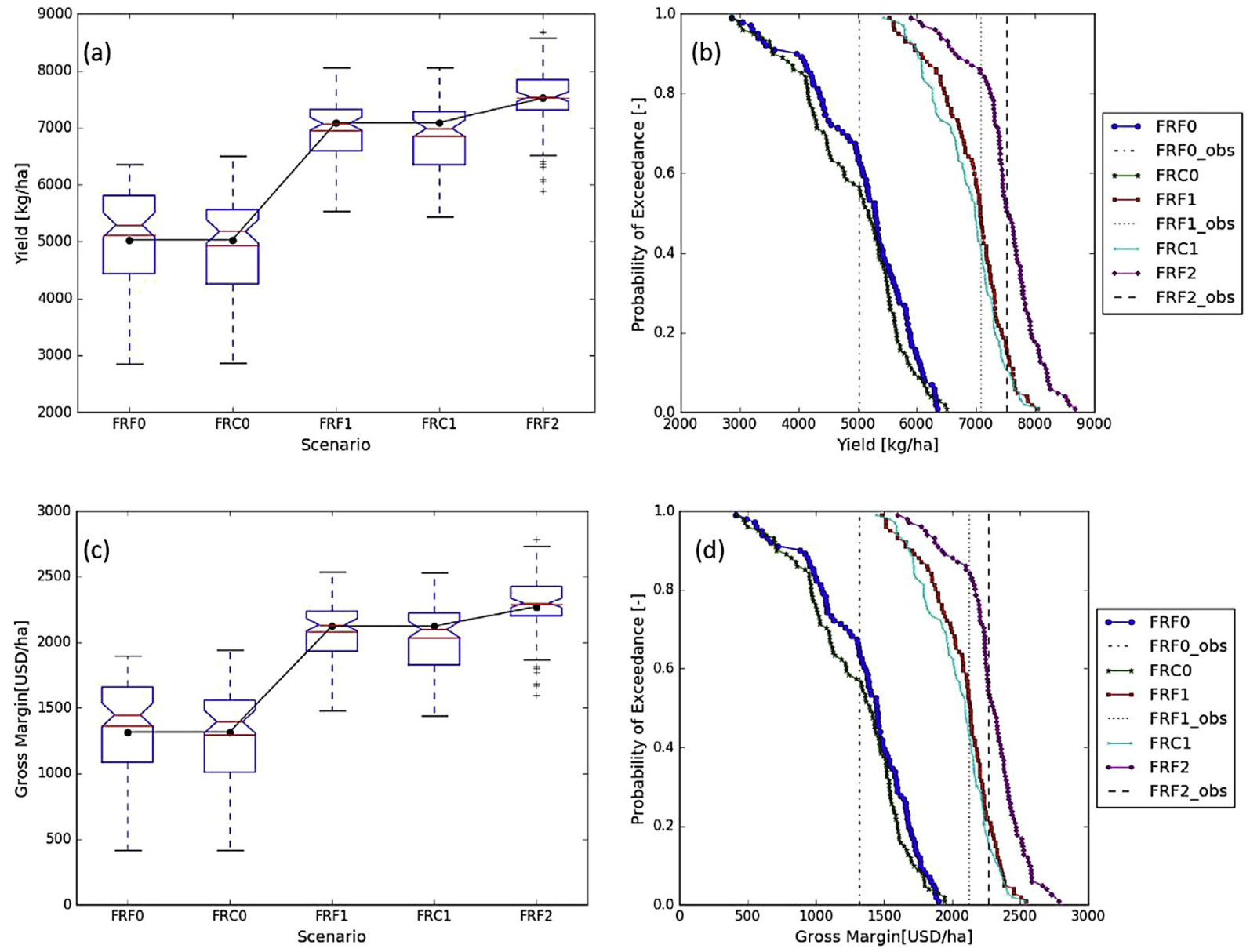

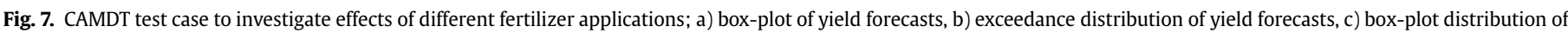

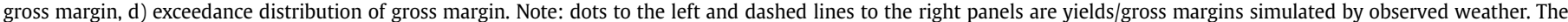

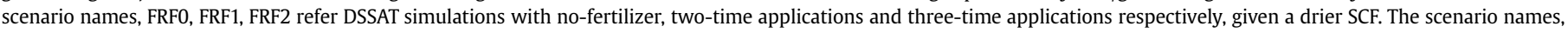
FRCO and FRC1 refer DSSAT simulations with no-fertilizer and two-time applications based on climatology. 


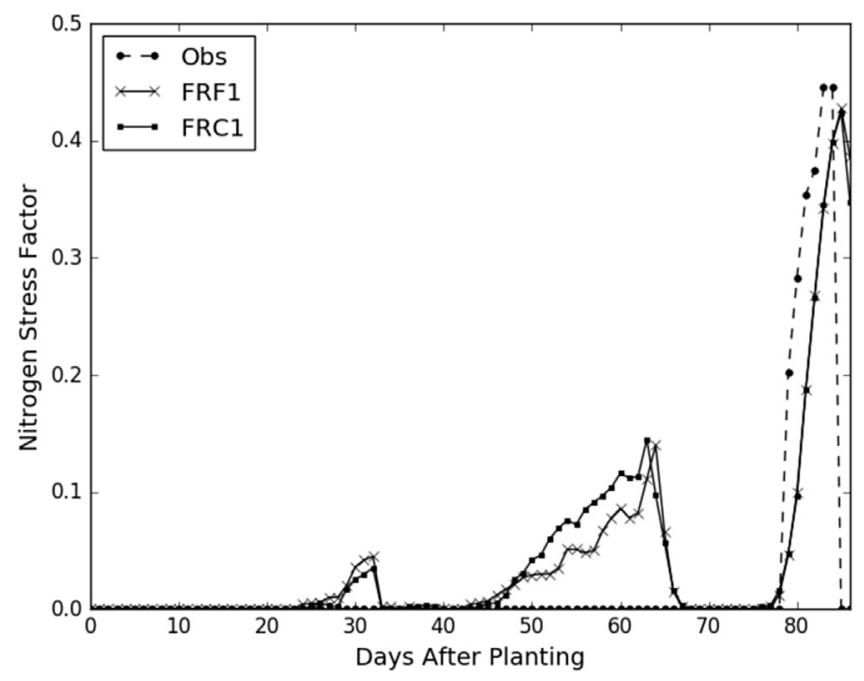

Fig. 8. Time-series of average nitrogen stress factor with two-time fertilizer application scenarios using SCF (FRF1), climatology (FRC1) and observed weather (Obs).

IRI's net assessment (http://iri.columbia.edu/our-expertise/ climate/forecasts/seasonal-climate-forecasts/) forecasted $95 \%$ of below-normal probability of rainfall due to super El Niño, which happened from the end of 2015 to early 2016.

Here, a dry forecast for DJF (55\% BN, 30\% NN and 15\% AN) affected by El Niño in 2010 was tested with no irrigation. Fertilizer was applied only once for all scenarios, $50 \mathrm{~kg}$ of $\mathrm{N} \mathrm{ha}^{-1}$ when transplanting. Other experimental settings including the temporal downscaling method are the same as Section 5.1.

Due to the lack of irrigation and drier weather, extremely low yields were obtained several times especially with mid- and late planting dates (Fig. 9a and b). Dry weather in January delayed flowering and thus maturity, which eventually led to poor growth and grain filling. The early planting (P35F) generated the highest mean and median of the forecasted yields but with high uncertainty (large variance). The late planting (P65F) resulted in lowest with some extremes. Predicted yields using observed weather (dots in Fig. 9a) showed more unfavorable weather as planting dates became closer to the end of December. Fig. 9c shows how the average water stress evolved during the crop growth. In the case of an early planting (P35F), the average water stress increased around the typical flowering dates for this cultivar (approximately 60 days after planting). However, P49F and P65F suffered water deficits even before flowering dates and for longer periods, which negatively affected crop growth and grain filling. Fig. 9d shows similarly but with a different indicator, i.e., the probability of exceeding 0.5 water stress threshold.

Additionally, we conducted the same experiment but with climatology information (i.e., 33\% BN, 34\% NN and 33\% AN) and the results are shown in Fig. 10. This experiment is to compare the situation when there is no indication of higher or lower seasonal rainfall for the coming season. In terms of mean yields, there is little difference between early (P35C) and mid (P49C) planting, but midplanting has more uncertainty. Compared to the simulation results with the dry forecast (Fig. 9a), distribution of simulated yields using climatology were more deviated from the simulated yield with observed weather indicated in greed dots (Fig. 10a). The simulation with dry forecast resulted in more water stress (Fig. 9c and d; Fig. 10c and d) leading lower yields than the climatology-based simulation. Again, this comparison shows merits of using SCF rather than climatology in the Bicol region. In this comparison, application of SCF does not apparently change the order of planting dates, which produces higher yields compared to climatologybased simulation. However, by applying SCF, we can have better idea on "relative" changes in yields with different planting dates.

\section{Discussion}

In the pursuit of advancing climate-smart agriculture, a number of agro-climate tools have been developed (Hansen and Coffey, 2011). For instance, Yield Prophet and AgroClimate mentioned above are extensive agricultural decision support systems which aim to collect and integrate wide ranges of information needed for crop production, analyze or transform the information using various simulation models, and provide recommendations for appropriate action. Unlike these tools, CAMDT has rather specific objectives, i.e., linking probabilistic seasonal climate forecast (SCF) directly to crop models (DSSAT-CSM-Rice model in this version), and to provide an easy-to-use graphical user interface that facilitates convenience simulating "what-if" scenarios for agricultural extension workers or advisors, and possible, farmers.

CAMDT was developed to target agricultural advisors or extension workers, unlike other DSS that directly targeted farmers (e.g., Churi et al., 2013). Limited knowledge on probabilistic SCF and crop simulation models may lead to misuse or misinterpret outputs of CAMDT. Nelson et al. (2002) emphasized the critical roles of intermediaries (agricultural advisors or consultants) in overcoming low adaptation rate of computer-based DSS and in connecting research to practice. To avoid misuse of CAMDT, potential users are encouraged to increase their understanding about crop simulation models, probability, and climate forecasts. To overcome this implementation problem of agricultural decision support systems (i.e., Rossi et al., 2014), several training workshops were conducted for potential users of CAMDT in the Philippines.

CAMDT is a desktop tool, unlike other web-based tools (e.g., AgroClimate). CAMDT is a standalone computer-based software designed mainly for conducting scenario analyses given SCF. However, under the Bicol Agri-Water Project (BAWP), which CAMDT is being developed, a Knowledge Sharing Portal and Maproom (KSPM; http://iridl.ldeo.columbia.edu/maproom/Water/ $\mathrm{BAWKP} /$ index.html) is also developed to disseminate higher-level information that can support decision making at various levels. General recommendations on farming options produced by operating CAMDT will be released to the public through KSPM.

Currently, CAMDT is being used to produce crop yield outlooks for the Seasonal Climate Forecast and Extension Advisory (CLEA) in the Bicol region, Philippines. CLEA is a two-page briefer that contains six-month climate outlook for the municipality and advisories on recommendations for planting and harvesting windows, crops or varieties to plant, and crop and water management practices suitable to the climate outlook, as provided by the Philippine Atmospheric, Geophysical and Astronomical Services Administration (PAGASA). It is released every onset of cropping season and updated on a monthly basis. Adoption and responses of farmers have been monitored and in 2016 it was reported that a total of 474 farmers and other stakeholders adopted CLEA as source of climate information and extension advisories for decision making in their farming activities.

Despite continuous efforts in developing better agricultural DSSs, usefulness of the DSSs remains relatively low (Matthews et al., 2008; McCown, 2002, 2012; Nguyen et al., 2007; Rossi et al., 2014; Stone and Hochman, 2004). In Rossi et al. (2014) the unsuccessful adoption of DSSs in agricultural community is ascribed to the factors, "profitability, user-friendly design, time requirement for DSS usage, credibility, adaptation of the DSS to the farm situation, information update, and level of knowledge of the user". We tackled some of those issues, specifically pursuing a user- 

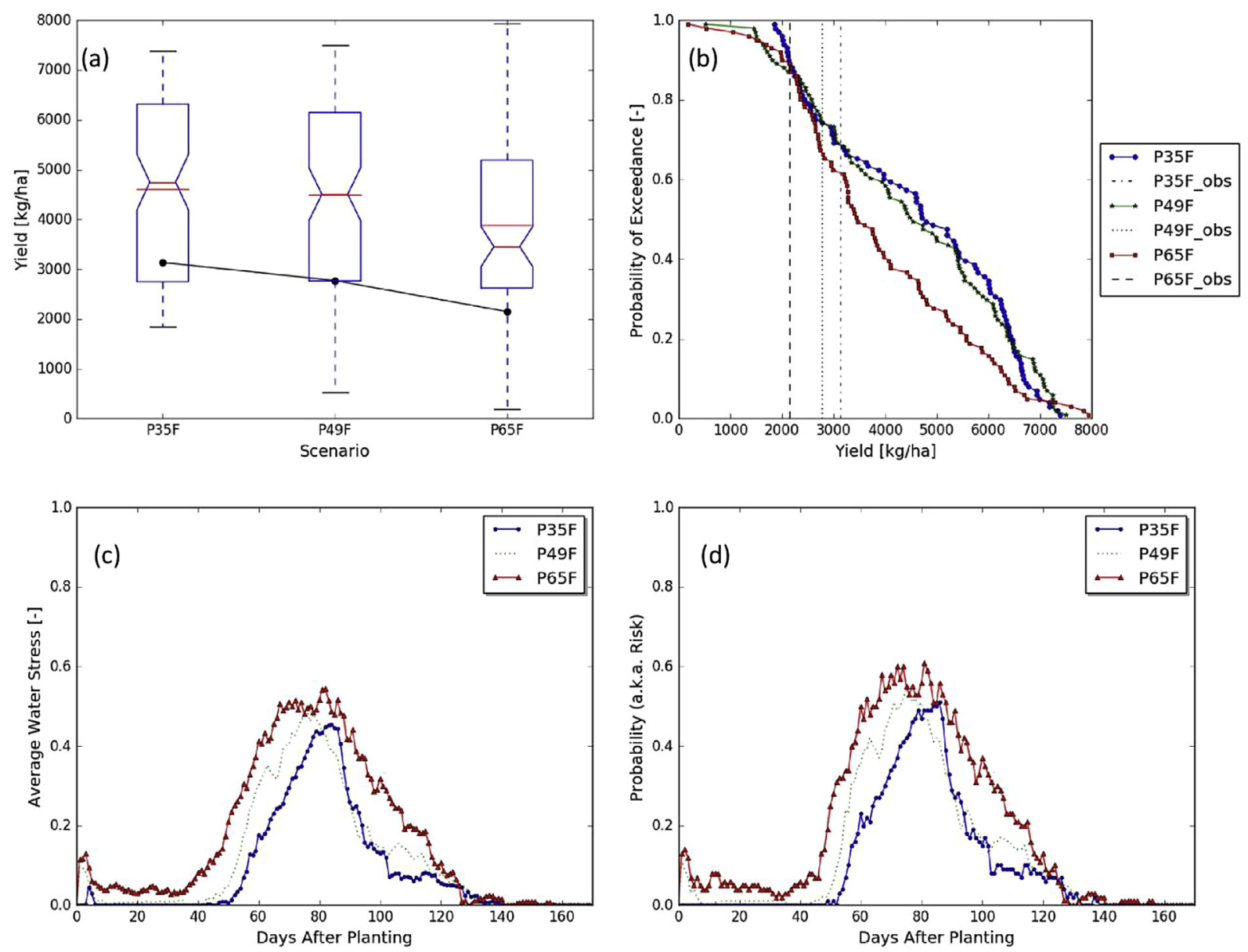

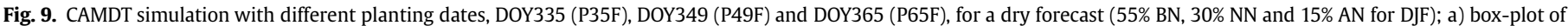

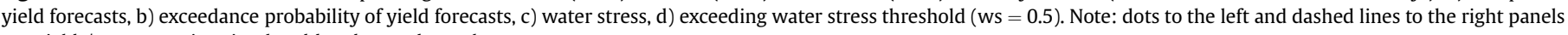
are yields/gross margins simulated by observed weather.

friendly design, easiness of DSS operation and circumventing timeconsuming data processing and repetitive model simulations.

It is important to use CAMDT in an appropriate way and interpret its outputs properly. CAMDT users should carefully examine if CAMDT produces reasonable fluctuations in yield for past events, specifically for seasons, which produced exceptionally low/high yields. The user should interpret the simulated yield in relative terms, not by deterministic values. In addition, CAMDT users should fully understand the concept of probability density function or cumulative distribution function to correctly interpret outputs of CAMDT and suggest recommendations for farmers. Basic statistical resources can help in understanding probability distributions (e.g., Haan, 2002).

CAMDT should be used mainly for exploring various options, which meet stakeholder's needs rather than trying to find an 'optimized' solution. This is also proven as a key proposition for successful implementation of a DSS in Hochman and Carberry (2011). Actual decisions on farm management, cultivar selection and how much risk/opportunities to take depend on the farmer, while CAMDT remains as a tool to be used by a farmer adviser, extension agent, agronomist, etc.

Nevertheless, it is always necessary to be cautious when delivering recommendations to farmers based on CAMDT by emphasizing the role of uncertainty. This could be associated with unavailability of required data (e.g., weather, soil, crop cultivar, scale, etc.). Lastly, it is important to note that crop growth and yield are affected by other factors besides rainfall. In this study, we considered only seasonal rainfall forecasts. If a target crop is sensitive to temperature, it is also possible to link seasonal temperature forecasts with crop simulation models. Since DSSAT does not simulate the effect of crop diseases, our future work includes integrating a disease simulation model with DSSAT-CSM-Rice model in order to take into account other critical factors. The current version of CAMDT shows only yield-related DSSAT outputs and water stress indices, but depending on users' demands, it can display other model outputs such as nitrogen loss or Leaf Area Index (LAI), or soil water content.

\section{Summary}

We introduced a software framework, CAMDT (Climate Agriculture Modeling and Decision Tool), which is designed to guide decision-makers in adopting appropriate crop and agricultural water management practices that can improve crop yields for given climatic conditions. CAMDT takes a seasonal climate forecast released with one to three months of lead-time and links it to the DSSAT-CSM-Rice model by downscaling to daily sequences of weather data. This approach informs decision-making for selecting agricultural management practices before or during the growing season and thus CAMDT is a useful tool that can be utilized in operational mode, especially in developing countries with high vulnerability to climate extremes. Two different downscaling tools 

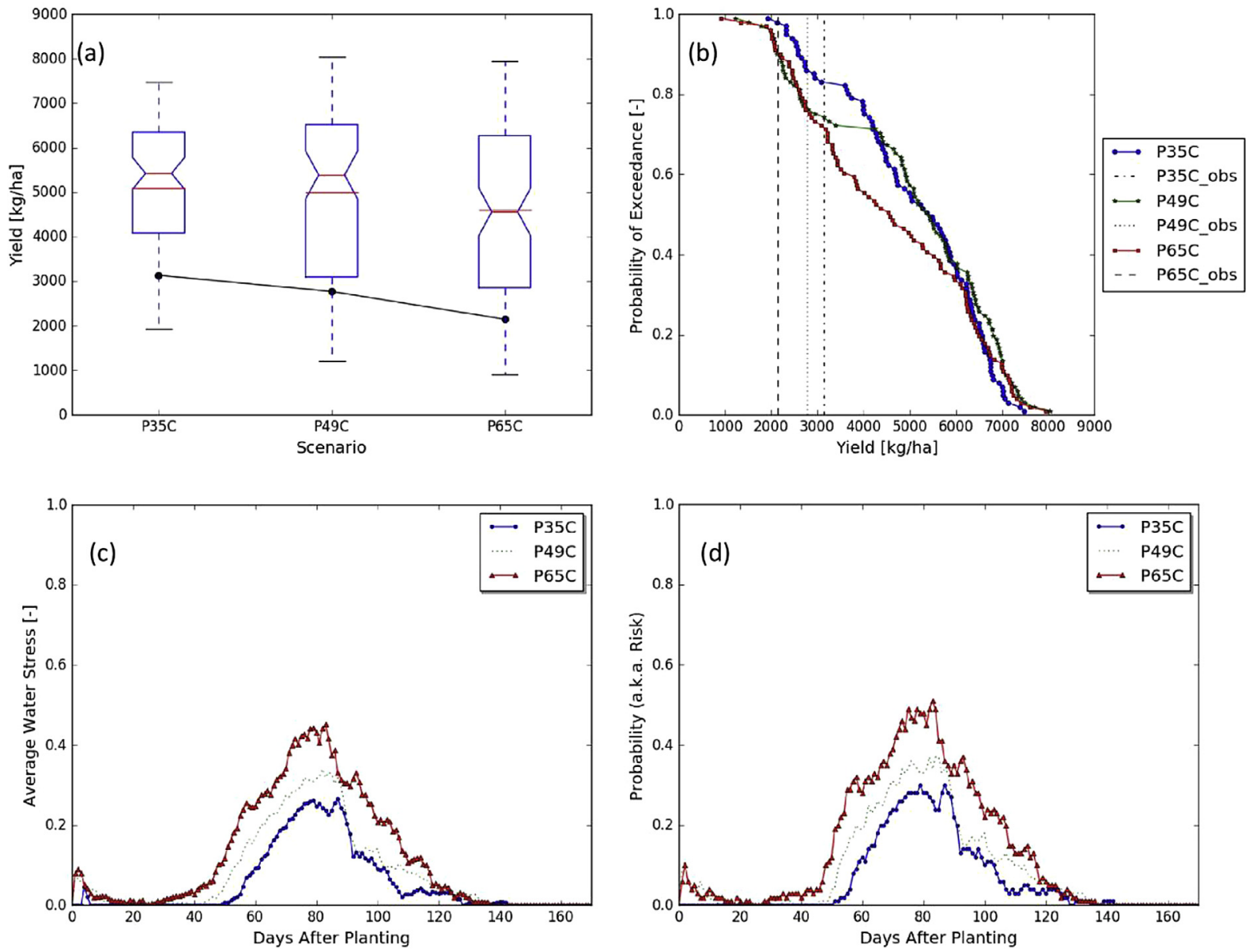

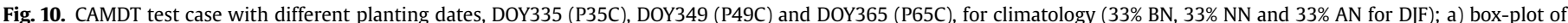

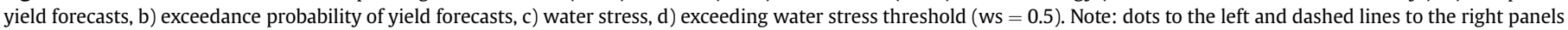
are yields/gross margins simulated by observed weather.

are implemented with CAMDT: FResampler1 as a non-parametric method and predictWTD as a parametric stochastic disaggregation method. The convenient graphical user interface of CAMDT assists users to provide essential input for the DSSAT-CSM-Rice model. Model-predicted yields based on seasonal climate forecasts are visualized through boxplots or exceedance probability curves reflecting uncertainties in the yield forecast. In addition, by providing expected cost and crop prices, users can perform simple economic analyses to estimate gains or losses depending on their management practices for a given SCF.

CAMDT is a practical tool, which connects seasonal climate information to a crop simulation model so that it can be applied for better risk management in agriculture with real-world applications. CAMDT was developed using a free open-source programming language, Python, and it can be easily customized for different types of crops, soil and weather stations, as well as adding other ways for visualizations or other functionalities if needed. CAMDT can be also used for meaningful research purposes. For example, the effects of different temporal downscaling methods (in this study, FResampler1 vs. predictWTD), or choosing different rainfall characteristics (i.e., rainfall amount, intensity or frequency) for constraining predictWTD can be also tested with ease.

\section{Acknowledgement}

This research was funded by the United States Agency for
International Development (USAID) (AID-492-G-12-00005) -Philippines for Bicol Agriculture Water Project in collaboration with the University of the Philippines Los Baños Foundation, Inc., (UPLBFI), Department of Agriculture (DA), Department of Agriculture, Philippine Atmospheric Geophysical and Astronomical Services Administration (PAGASA), and other local partners. We acknowledge Bradfield Lyon for the CPT simulations and Prakash Jha for assistance in crop model calibration. We thank PhilRice for the rice datasets. We also thank the editors and three anonymous reviewers for helping us improve the quality of the paper. Development of FResampler1 was funded in part by NASA-SERVIR Grant NNN13D788T.

\section{References}

Ahmad, S., et al., 2012. Application of the CSM-CERES-rice model for evaluation of plant density and nitrogen management of fine transplanted rice for an irrigated semiarid environment. Precis. Agric. 13 (2), 200-218.

Amiri, E., Rezaei, M., Bannayan, M., Soufizadeh, S., 2013. Calibration and evaluation of CERES rice model under different nitrogen-and water-management options in semi-mediterranean climate condition. Commun. soil Sci. plant analysis 44 (12), 1814-1830.

Apipattanavis, S., Bert, F., Podesta, G., Rajagopalan, B., 2010. Linking weather generators and crop models for assessment of climate forecast outcomes. Agric. For. meteorology 150 (2), 166-174.

Barnston, A.G., He, Y., Unger, D.A., 2000. A forecast product that maximizes utility for state-of-the-art seasonal climate prediction. Bull. Am. Meteorological Soc. 81 (6), 1271

Basak, J.K., Ali, M.A., Islam, M.N., Alam, M.J.B., 2009. Assessment of the effect of climate change on boro rice production in Bangladesh using CERES-rice model. 
In: Proceedings of the International Conference on Climate Change Impacts and Adaptation Strategies for Bangladesh, pp. 103-113.

Brown, M.E., Funk, C.C., 2008. Food security under climate change. Science 319 (5863), 580-581. http://dx.doi.org/10.1126/science.1154102.

Buishand, T.A., Brandsma, T., 2001. Multisite simulation of daily precipitation and temperature in the Rhine basin by nearest-neighbor resampling. Water Resour. Res. 37 (11), 2761-2776.

Capa, M., et al., 2015. Linking seasonal climate forecasts with crop models in Iberian Peninsula. In: EGU General Assembly Conference Abstracts, p. 15278.

Churi, A.J., Mlozi, M.R., Mahoo, H., Tumbo, S.D., Casmir, R., 2013. A decision support system for enhancing crop productivity of smallholder farmers in semi-arid agriculture. Int. J. Inf. 3 (8).

Clark, M.P., et al., 2004. A resampling procedure for generating conditioned daily weather sequences. Water Resour. Res. 40 (4).

Elazegui, D.D., Rola, A.C., Allis, E., 2016. Enhancing institutional dynamics for multiple uses of water amidst climate-related risks: the case of Lake Buhi, Philippines. Lakes Reservoirs Res. Manag. 21 (3), 224-234.

Ella, V.B., Fajardo, A.L., Elazegui, D.D., 2010. Policy analysis of irrigation issues in regions 4a, 4b and 5. Dep. Agric. Bureau Agric. Res.

Fraisse, C., et al., 2006. AgClimate: a climate forecast information system for agricultural risk management in the southeastern USA. Comput. Electron. Agric. 53 (1), 13-27.

Haan, C.T. 2002. Statistical Methods in Hydrology. The Iowa State University Press.

Han, E., Ines, A.V., 2015. In: Some Advances in Downscaling Probabilistic Climate Forecasts for Agricultural Decision Support, 2015 AGU Fall Meeting. Agu. http:// adsabs.harvard.edu/abs/2015AGUFMGC53G1293H.

Hansen, J., Coffey, K., 2011. Agro-climate Tools for a New Climate-smart Agriculture. https://ccafs.cgiar.org/sites/default/files/assets/docs/iri_agro-climate_tools_ brief-web.pdf.

Hansen, J.W., 2005. Integrating seasonal climate prediction and agricultural models for insights into agricultural practice. Philosophical Trans. R. Soc. Lond. B Biol. Sci. 360 (1463), 2037-2047.

Hansen, J.W., Indeje, M., 2004. Linking dynamic seasonal climate forecasts with crop simulation for maize yield prediction in semi-arid Kenya. Agric. For. Meteorology 125 (1), 143-157.

Hansen, J.W., Ines, A.V., 2005. Stochastic disaggregation of monthly rainfall data for crop simulation studies. Agric. For. Meteorology 131 (3), 233-246.

Hansen, J.W., Mason, S.J., Sun, L., Tall, A., 2011. Review of seasonal climate forecasting for agriculture in sub-Saharan Africa. Exp. Agric. 47 (2), 205.

Hochman, Z., Carberry, P., 2011. Emerging consensus on desirable characteristics of tools to support farmers' management of climate risk in Australia. Agric. Syst. 104 (6), 441-450.

Hochman, Z., et al., 2009. Re-inventing model-based decision support with Australian dryland farmers. 4. Yield Prophet ${ }^{\mathbb{R}}$ helps farmers monitor and manage crops in a variable climate. Crop Pasture Sci. 60 (11), 1057-1070.

Hoogenboom, G., et al., 2015. Decision Support System for Agrotechnology Transfer (DSSAT) Version 4.6. DSSAT Foundation, Prosser, Washington. http://dssat.net.

Ines, A.V., Hansen, J.W., Robertson, A.W., 2011. Enhancing the utility of daily GCM rainfall for crop yield prediction. Int. J. Climatol. 31 (14), 2168-2182.

Ines, A.V.M., 2013. FResampler1: A Resampling and Downscaling Tool for Seasonal Climate Forecasts. IRI/Columbia Univ., NY, USA.

Ines, A., Han, E., 2014. PredictWTD: A Temporal Downscaling Tool for Seasonal Climate Forecasts. IRI/Columbia University, NY, US.

Jones, J.W., et al., 2003. The DSSAT cropping system model. Eur. J. Agron. 18 (3), 235-265.

Jose, A.M., Francisco, R.V., Cruz, N.A., 1999. A Study on the Impact of Climate Variability/Change on Water Resources in the Philippines. Philippine Institute for Development Studies.

Kim, Y., Rajagopalan, B., Lee, G., 2016. Temporal statistical downscaling of precipitation and temperature forecasts using a stochastic weather generator. Adv. Atmos. Sci. 33 (2), 175-183.

Koide, N., et al., 2013. Prediction of rice production in the Philippines using seasonal climate forecasts. J. Appl. Meteorology Climatol. 52 (3), 552-569.
Lobell, D.B., et al., 2008. Prioritizing climate change adaptation needs for food security in 2030. Science 319 (5863), 607-610.

Lyon, B., Camargo, S.J., 2009. The seasonally-varying influence of ENSO on rainfal and tropical cyclone activity in the Philippines. Clim. Dyn. 32 (1), 125-141.

Lyon, B., Cristi, H., Verceles, E.R., Hilario, F.D., Abastillas, R., 2006. Seasonal reversal of the ENSO rainfall signal in the Philippines. Geophys. Res. Lett. 33 (24).

Lyon, B., Ines, A., 2014. Seasonal forecast development for applications in bicol. In: Technical workshop on models and tools for water, agriculture and knowledge sharing - Bicol Agri-Water Project, Naga City, Philippines.

Mahmood, R., Meo, M., Legates, D.R., Morrissey, M.L., 2003. The CERES-rice modelbased estimates of potential monsoon season rainfed rice productivity in Bangladesh. Prof. Geogr. 55 (2), 259-273.

Mason, S.J., Goddard, L., 2001. Probabilistic precipitation anomalies associated with ENSO. Bull. Am. Meteorological Soc. 82 (4), 619.

Mason, S.J., Tippett, M.K., 2016. Climate Predictability Tool Version 15.3. Columbia University Academic Commons, New York, U.S.A.

Matthews, K., Schwarz, G., Buchan, K., Rivington, M., Miller, D., 2008. Wither agricultural DSS? Comput. Electron. Agric. 61 (2), 149-159.

McCown, R., 2012. A cognitive systems framework to inform delivery of analytic support for farmers' intuitive management under seasonal climatic variability. Agric. Syst. 105 (1), 7-20.

McCown, R.L., 2002. Changing systems for supporting farmers' decisions: problems paradigms, and prospects. Agric. Syst. 74 (1), 179-220.

Nelson, R., Holzworth, D., Hammer, G., Hayman, P., 2002. Infusing the use of seasonal climate forecasting into crop management practice in North East Australia using discussion support software. Agric. Syst. 74 (3), 393-414.

Nguyen, N.C., Wegener, M., Russell, I., 2007. Decision support systems in Australian agriculture: state of the art and future development. Aust. Farm Bus. Manag. J. 4 $(1 / 2), 15$.

Pal, R., et al., 2013. Application of seasonal temperature and rainfall forecast for wheat yield prediction for Palampur, Himachal Pradesh. Int. J. Agric. Food Technol. 4 (5), 453-460.

Pinnschmidt, H., Batchelor, W., Teng, P., 1995. Simulation of multiple species pest damage in rice using CERES-rice. Agric. Syst. 48 (2), 193-222.

Ritchie, J., Singh, U., Godwin, D., Bowen, W., 1998. Cereal Growth, Development and Yield, Understanding Options for Agricultural Production. Springer, pp. 79-98.

Romero, C.C., et al., 2012. Reanalysis of a global soil database for crop and environmental modeling. Environ. Model. Softw. 35, 163-170.

Rossi, V., Salinari, F., Poni, S., Caffi, T., Bettati, T., 2014. Addressing the implementation problem in agricultural decision support systems: the example of vite. net ${ }^{\circledR}$. Comput. Electron. Agric. 100, 88-99.

Saseendran, S., Singh, K., Rathore, L., Singh, S., Sinha, S., 2000. Effects of climate change on rice production in the tropical humid climate of Kerala, India. Clim. Change 44 (4), 495-514.

Schmidhuber, J., Tubiello, F.N., 2007. Global food security under climate change. Proc. Natl. Acad. Sci. 104 (50), 19703-19708.

Shafiee-Jood, M., Cai, X., Chen, L., Liang, X.Z., Kumar, P., 2014. Assessing the value of seasonal climate forecast information through an end-to-end forecasting framework: application to US 2012 drought in central Illinois. Water Resour. Res. 50 (8), 6592-6609.

Stone, P., Hochman, Z., 2004. If interactive decision support systems are the answer have we been asking the right questions, New directions for a diverse planet. In: Proceedings of the 4th International Crop Science Congress.

Verdin, A., Rajagopalan, B., Kleiber, W., Podestá, G., Bert, F., 2015. A conditional stochastic weather generator for seasonal to multi-decadal simulations. J. Hydrology in press, available online: 23 Dec 2015, https://doi.org/10.1016/j. jhydrol.2015.12.036.

Wilks, D., 2002. Realizations of daily weather in forecast seasonal climate. J. Hydrometeorol. 3 (2), 195-207.

Yates, D., Gangopadhyay, S., Rajagopalan, B., Strzepek, K., 2003. A technique for generating regional climate scenarios using a nearest-neighbor algorithm. Water Resour. Res. 39 (7). 